\title{
O ARQUIVISTA COMO MEDIADOR DA INFORMAÇÃO E SUA INTERVENÇÃO PARA A TOMADA DE DECISÃO: UM ESTUDO DE CASO NO ESCRITÓRIO DE CONTABILIDADE CONPOR
}

\author{
THE ARCHIVIST AS A MEDIATOR OF THE \\ INFORMATION AND ITS INTERVENTION FOR THE \\ DECISION MAKING: A CASE STUDY AT CONPOR \\ ACCOUNTING OFFICE
}

\author{
Victor de Souza Ramosa \\ Raquel do Rosário Santos ${ }^{b}$ \\ Ingrid Paixão de Jesusc
}

\begin{abstract}
RESUMO
Introdução: A mediação da informação realizada pelo arquivista no escritório de contabilidade, auxiliando os contadores para as tomadas de decisões é o tema deste trabalho. Objetivo: Analisar quais os fatores que contribuem para que o arquivista de um escritório de contabilidade medeie à informação e auxilie o contador nas tomadas de decisões. Metodologia: Foi adotada a técnica de observação direta sistemática para mapear e descrever as atividades desenvolvidas pelo arquivista no escritório contábil, bem como identificar elementos de ambiência que favorecem o processo de mediação da informação, para isso, esta pesquisa foi desenvolvida a partir do estudo de caso realizado no escritório de contabilidade Conpor. Aplicou-se também um questionário junto aos contadores do escritório, no intuito de verificar a existência do processo de intervenção do arquivista na tomada de decisão do contador. Resultados: Entre as ações de maior visibilidade que identificam o arquivista como mediador da informação em um ambiente contábil está às atividades técnicas, bem como à ambiência e à comunicação estabelecida entre o arquivista e os contadores. Conclusão: É preciso que 0 arquivista busque ser percebido na instituição contábil como um profissional que agrega valor às tomadas de decisões por meio da mediação direta e indireta da informação.
\end{abstract}

Descritores: Mediação da informação. Arquivo contábil. Arquivista - Tomada de

\footnotetext{
a Mestrando em Ciência da Informação e arquivista pela Universidade Federal da Bahia (UFBA). E-mail: victor@outlook.com

b Doutora em Ciência da Informação pela Universidade Federal da Paraíba. Docente do Instituto de Ciência da Informação e do Programa de Pós-Graduação em Ciência da Informação da Universidade Federal da Bahia (UFBA). E-mail: quelrosario@gmail.com

c Mestranda em Ciência da Informação e bibliotecária pela Universidade Federal da Bahia (UFBA). E-mail: ingridpaixao191@gmail.com.
} 
decisões.

\section{INTRODUÇÃO}

A atuação dos arquivistas vai além da custódia, organização e controle de acesso aos documentos orgânicos. Possuindo conhecimento no que diz respeito à análise, recuperação e disseminação da informação, os arquivistas são também agentes mediadores na relação entre o usuário e a informação. Sabendo-se disso e das constantes mudanças nos meios tecnológicos, informacionais e comunicacionais que influenciam diretamente o ambiente empresarial, torna-se relevante para o arquivista o entendimento de que eles estão inseridos no contexto da Ciência da Informação.

Nessa perspectiva, ao observar as interferências realizadas pelo arquivista no ambiente empresarial, como, por exemplo, os escritórios de contabilidade, em que os conflitos informacionais estão mais propícios a acontecer - afinal é grande o número de dados, informações e documentos que são gerados e/ou acumulados - vê-se que estes profissionais devem ir além do cuidado e tratamento do acervo documental contábil. É preciso que os arquivistas se atentem também às ações diretas de mediação da informação, conforme conceito defendido por Almeida Júnior (2015), tais ações permitem um fortalecimento das relações entre os usuários e as informações, auxiliando assim os contadores para as tomadas de decisões.

Dessa forma, a presente comunicação teve como objetivo geral analisar quais os fatores que contribuem para que o arquivista de um escritório de contabilidade medeie a informação e auxilie o contador nas tomadas de decisões. Para tanto, o universo de investigação foi o escritório de contabilidade Conpor, localizado na cidade de Salvador e que possui no seu quadro de funcionários sete (7) contadores e um (1) arquivista. A escolha pelo referido escritório contábil como caso desta investigação se justifica pelo fato de ser o local de trabalho de um dos autores desta pesquisa, portanto o critério para a seleção do caso foi por acessibilidade e intencionalidade.

Quanto ao delineamento metodológico, configura-se como um estudo de 
caráter descritivo e natureza quanti-qualitativa, realizado por meio de estudo de caso pautado na investigação sobre a mediação da informação e das contribuições do arquivista no ambiente do escritório de contabilidade Conpor. Vale acrescentar que foram adotadas para a coleta de dados as técnicas de observação sistemática direta e aplicação de questionário.

Dessa forma, percebeu-se que alguns elementos, como o da ambiência, representam fatores que contribuem para o entendimento do arquivista como um agente mediador no escritório contábil. Conclui-se que ao desenvolverem as atividades de mediação da informação direta e indireta, que devem ser percebidas pela instituição contábil, os arquivistas conseguem também auxiliar os contadores nas tomadas de decisão.

\section{MEDIADOR DA INFORMAÇÃO: O ARQUIVISTA NO ESCRITÓRIO CONTÁBIL}

Destacar o conceito de mediação da informação é o aspecto inicial para compreender o papel do arquivista enquanto mediador da informação dentro de um ambiente empresarial. Ao discorrer sobre esse conceito, Almeida Junior (2015) é o principal aporte teórico para os diversos autores da área da Ciência da Informação. De acordo com o autor supracitado

Mediação da informação é toda ação de interferência - realizada em um processo, por um profissional da informação e na ambiência de equipamentos informacionais -, direta ou indireta; consciente ou inconsciente; singular ou plural; individual ou coletiva; visando a apropriação de informação que satisfaça, parcialmente e de maneira momentânea, uma necessidade informacional, gerando conflitos e novas necessidades informacionais. (ALMEIDA JUNIOR, 2015, p. 25).

Pontua-se dessa conceituação que mediar pressupõe tanto uma ideia de ação quanto de interferência, não sendo apenas uma ligação estática entre dois extremos. Mediação da informação é, então, um ato reflexivo e produtivo, pois está inserida em um processo que se relaciona ao conjunto de ações e sistemas auxiliando o profissional da informação a interferir e atender as necessidades informacionais dos usuários.

Nesta perspectiva, torna-se relevante dizer que um dos conjuntos de 
ações e sistemas do processo de mediação envolve a comunicação, que, segundo Gomes e Santos (2009), é conceituada como um processo de compartilhamento que permite a circulação de ideias entre os saberes e os sujeitos. A comunicação, então, é basilar para que a mediação da informação seja realizada, em todas as suas etapas e processos. É preciso salientar, entretanto, que o processo de mediação da informação vai além da comunicação, devendo estar relacionada também a todas as outras ações e sistemas, incluindo as de caráter subjetivos que o mediador deve apresentar para, assim, permitir a criação de sentidos entre os interlocutores.

Ao tratar o profissional da informação como o agente mediador da informação, o conceito trazido anteriormente, de Almeida Junior (2015), permite inferir que o arquivista, que utiliza da informação arquivística como objeto de estudo, pode ser considerado um mediador da informação. É importante destacar, porém, as duas condições as quais Lopez (2008), atribui àquele responsável pelo arquivo no cenário brasileiro. Para ele, existe o "estar" e o "ser" arquivista. O primeiro, o "estar arquivista", é vinculado a um estado ou situação: é o profissional, seja ele qual for, que trabalha no arquivo e com os documentos arquivísticos. Já o segundo, o "ser arquivista", diz respeito ao profissional de formação, ou seja, àquele que, independentemente de trabalhar no arquivo, é indicado como arquivista. Nesse sentido, vale destacar que a compreensão do arquivista como agente mediador se aplica quando este profissional realiza a interferência, de maneira consciente, tanto com fundamentação teórica quanto com base em sua vivência profissional, favorecendo sua relação com os sujeitos sociais.

Outro aspecto que deve ser levado em consideração, ainda do conceito apresentado de mediação da informação (ALMEIDA JÚNIOR, 2015), é o da ambiência de equipamentos informacionais. Destaca-se que está vai além do espaço físico. Sendo assim, os valores subjetivos do mediador são essenciais para a formação de uma ambiência adequada no processo de mediação da informação. Almeida Junior (2016) acrescenta ainda que o mediador, ao influenciar e interferir na ambiência, modifica a ideia que os equipamentos informacionais são lugares fechados. Assim, por meio da ambiência dos espaços 
informacionais, como o arquivo, o sujeito desperta e desenvolve o prazer, desejo, gosto e a vontade para ler, estudar, analisar as informações que tem acesso e que necessita para seu exercício social, portanto, mais que um ambiente fisicamente confortável, o arquivo também deve apresentar aspectos subjetivos que auxiliem no "encontro" entre o sujeito e a informação.

No que tange ao objetivo da mediação da informação, um dos resultados desse processo é a apropriação da informação que permite atender não só a uma necessidade informacional, que possui o caráter utilitarista e imediata, mas também, uma conscientização do sujeito em relação ao quê a informação significará para a vida dele. A partir de uma efetiva mediação da informação, não só uma necessidade informacional é atendida, mas também é gerado o conhecimento, que propicia os conflitos e novas necessidades informacionais, conforme defende Almeida Junior (2015).

No que diz respeito às atividades da mediação da informação, para Almeida Junior (2015) existe a "mediação indireta da informação" e a "mediação direta da informação". A primeira, a mediação indireta, refere-se as atividades que são desenvolvidas sem a presença física e imediata dos usuários. Já a segunda, a mediação direta a presença real do usuário é inevitável para o desenvolvimento das atividades. No âmbito da Arquivologia, são exemplos da mediação indireta da informação: o armazenamento e processamento das informações e a política do desenvolvimento do acervo; já como exemplo da mediação direta: as atividades arquivísticas no contexto do acesso aos serviços, promoções de ações culturais e diálogos, com objetivo de apoiar o usuário no desenvolvimento de competências em informação.

Ampliando as discussões em torno dessa temática, Gomes (2014, 2016, 2017) defende a existência de cinco dimensões da mediação da informação que permeiam o papel do mediador e as classifica como: dialógica, formativa, ética, estética e política. Ao explanar sobre as dimensões dialógica e formativa, Gomes $(2014,2016,2017)$ evidencia o cenário de atuação do processo de mediação. A dialogia propicia os espaços de interação que, por sua vez, permite a apropriação da informação e consequentemente possibilita a geração de novos saberes e conhecimentos. Isso leva o sujeito a desenvolver o protagonismo 
social. Salienta-se que esse protagonismo não é apenas voltado aos usuários, mas também ao mediador. O mediador, seja ele um arquivista ou não, precisa ter consciência de seu protagonismo social, afinal ele aproxima agentes e dispositivos informacionais gerando o processo de mediação, que está ligado ao ato de cuidar e de atender a uma necessidade informacional. Gomes (2016, p. 100) ratifica isso ao afirmar que,

Desse modo, o mediador coloca-se como um sujeito implicado no processo de mediação, se responsabilizando por ele e aperfeiçoando seu próprio perfil de protagonista, o que mais uma vez ressalta a dimensão formativa da mediação.

A dimensão ética da mediação da informação, de acordo com Gomes $(2014,2016,2017)$ traz a ideia de que o mediador deve possuir um autoconhecimento e uma disponibilidade de conhecer o outro, permitindo que este sujeito mediador desenvolva estratégias e explore suas potencialidades no processo de mediar. Ao conquistar isso, o mediador alcança o prazer estético, reconhece a beleza do construído, da apropriação e geração de novos conhecimentos. Sendo assim, para Gomes (2014, 2016, 2017), a dimensão da estética está ligada às percepções dos envolvidos no processo de mediação. É válido destacar que o sujeito mediador deve considerar que a mediação aproxima ao menos dois polos interlocutores e protagonistas do processo. Para isso, além do domínio da linguagem e de dispositivos de comunicação, as subjetividades dos envolvidos devem ser captadas e entendidas pelo mediador, possibilitando assim a construção do conhecimento.

Já, sobre a dimensão política, Gomes $(2016,2017)$ aborda que esta é uma consequência das demais dimensões e se caracteriza ao trazer o agente mediador como um agente político, uma vez que ele, como um protagonista social, age, constrói e interfere no meio. Diante disso, ao atuar como mediador da informação de forma consciente, o profissional da informação, a exemplo do arquivista, alcança a dimensão política que é essencial para a efetividade do processo de mediação, e, consequentemente para a produção de conhecimento no campo de atuação profissional ao qual o arquivista se encontra.

É importante destacar que ao considerar o profissional do arquivo como agente mediador da informação, tal profissional deve se ater ao contexto e 
ambiente ao qual se encontra a produção e/ou acumulação documental e informacional. Nos escritórios de contabilidade, o arquivista, então, deve conhecer, além das regulamentações da sua profissão - como por exemplo, a Lei ํo 6.546 de 1978, que estabelece quais as contribuições dos profissionais arquivistas -, os aspectos que envolvem a disciplina da contabilidade e que serão dispositivos para que eles adotem estratégias para a mediar a informação no ambiente.

Nesse intuito, a informação contábil, que de acordo com Yamonoto e Salotti $(2006$, p. 6) é "[...] aquela que altera o estado da arte e do conhecimento de seu usuário em relação à empresa e, a partir de interpretações, a utiliza na solução de problemas [...]", deve estar relacionada como uma informação orgânica, a qual Rousseau e Couture (1998, p. 63-64) definem como "[...] aquela elaborada, expedida ou recebida no âmbito da missão de um organismo." Ou seja, pelo fato de ser uma informação orgânica, é o arquivista o profissional que possui competências para organizar e disseminar a informação contábil.

Ainda em relação às características que envolvem o arquivo contábil é necessário salientar que os escritórios de contabilidade, de acordo com Vieira (2012) e Silva (2015) são, geralmente, estruturado em 3 (três) principais departamentos que desempenham diferente atividades e consequentemente produzem e/ou acumulam diferentes tipos documentais, estes são: contábil, fiscal e pessoal. Portanto, cabe ao profissional qualificado, arquivista, identificar as atividades dos contadores que possibilitam a produção documental e as atividades que dependem de informações contidas em documentos, para que assim, seja feita a mediação da informação contábil.

Observa-se que há uma constante mudança nas atividades exercidas pelo profissional contábil e isso merece atenção dos arquivistas, já que tal procedimento afeta a metodologia de trabalho desse profissional para a obtenção e mediação da informação contábil. Nesse sentido, justifica-se a necessidade do desenvolvimento de pesquisas que tratem da mediação da informação no âmbito de arquivos especializados, como da área contábil, o que motivou as escolhas deste estudo e o estabelecimento dos procedimentos metodológicos apresentados na próxima seção. 


\section{PROCESSO METODOLÓGICO}

Este estudo se caracteriza como uma abordagem descritiva, pois, ao investigar a rotina do trabalho dos profissionais do ambiente contábil, o objetivo primordial foi a descrição das características de determinada população ou fenômeno (GIL, 2002). Como método, adotou-se o estudo de caso por se tratar do escritório de contabilidade Conpor, localizado em Salvador, capital baiana, como cenário para descrição e estudo dos sujeitos.

Nesse sentido, esta pesquisa teve como objetivo geral analisar quais os fatores que contribuem para que o arquivista de um escritório de contabilidade possa realizar uma mediação da informação de maneira efetiva, auxiliando o contador em suas atividades profissionais e informacionais. Para alcançar 0 objetivo geral foram elencados os seguintes objetivos específicos: a) mapear e descrever as atividades de mediação da informação indiretas e diretas desenvolvidas pelo arquivista no escritório contábil; b) identificar os elementos de ambiência que favorecem o processo de mediação da informação contábil; c) verificar se existe um processo de interferência do arquivista na tomada de decisão do contador.

A partir dos objetivos específicos a) e b) foi utilizado a técnica de observação sistemática direta, também chamada de observação estruturada, planejada e controlada, em que o observador sabe o que procura e o que carece de importância em determinada situação (MARCONI; LAKATOS, 2007). A observação sistemática foi realizada com a utilização de um formulário padronizado em que foi registrada a análise e as informações identificadas no ambiente.

O formulário em questão foi previamente elaborado contendo 45 itens, dividido em três (3) partes: "Identificação e localização", "Espaços Informacionais", e "Fluxo Informacional". Vale acrescentar que os recursos fotográficos para ilustração e complementação dos registros e a experiência do agente mediador, que atua na instituição desde 2014, auxiliou na identificação das informações necessárias para o preenchimento do formulário.

Em relação ao objetivo específico c) utilizou-se a técnica de aplicação de 
questionário, este foi elaborado contendo 13 perguntas, e organizado em três (3) partes: "identificação do profissional"; "acesso à informação no escritório" e "intervenção do arquivo e arquivista na tomada de decisão do contador". O questionário foi entregue presencialmente aos sete (7) contadores do escritório de contabilidade da Conpor. É importante destacar que foi feita uma leitura completa de todo o questionário, antes da entrega para os contadores, a fim de verificar se existiam dúvidas a respeito de alguma das perguntas.

Feita a observação e tendo as respostas dos questionários, os dados foram tratados a partir das abordagens qualitativa e quantitativa. Ou seja, após a conclusão da coleta de dados foram feitas as leituras e análises dos formulários preenchidos e dos questionários respondidos, identificando os dados quantificáveis e as informações e fotografias para tratamento qualitativo. Vale ressaltar que os dados identificados como quantificáveis foram tratados através do Microsoft Excel 2010.

\section{A MEDIAÇÃO DA INFORMAÇÃO NO ESCRITÓRIO DE CONTABILIDADE CONPOR}

Primeiramente, é preciso destacar que o escritório de contabilidade Conpor foi fundado em 1991 em Salvador, Bahia, e é especializado nos serviços fiscal, contábil e pessoal de empresas de pequeno porte. Atendendo atualmente 65 empresas de diferentes ramos de atividades, nos âmbitos da construção civil, restaurantes, clínicas médicas, entre outros, a Conpor possui oito (8) profissionais em sua equipe.

A sala de arquivo e a sala dos contadores são dois espaços informacionais da Conpor que merecem destaque na pesquisa em questão. A sala de arquivo foi construída e organizada no ano de 2016. Neste espaço é armazenado e preservado os documentos arquivísticos correntes e intermediários das organizações que são clientes da Conpor. Já a sala dos contadores é o espaço onde estão localizadas as mesas de trabalho dos profissionais do escritório. É um espaço informacional, pois, é neste ambiente que os contadores, geralmente produzem as documentações e transitam com as 
documentações correntes.

Posteriormente, enquanto sujeitos desta pesquisa foram selecionados 0 agente mediador da informação e os contadores do escritório de contabilidade. O primeiro, o agente mediador da informação na Conpor, corresponde ao arquivista da empresa, sendo esse o único funcionário que presta assistência administrativa. Já os demais, os contadores da Conpor, correspondem aos profissionais que ao desempenhar funções específicas nos setores da Contabilidade e que são impactados pelo resultado do processo de mediação da informação. Dentre os contadores, três (3) estão alocados no Setor Pessoal, dois (2) no Setor Fiscal os outros dois (2) no Setor Contábil.

Nesse contexto, com o intuito de atender o primeiro objetivo específico proposto, foi feita a observação direta para obter dados que evidenciassem a identificação das atividades de mediação da informação desenvolvidas pelo arquivista no escritório de contabilidade.

\subsection{As Atividades do Mediador da INFORMação Na CoNPOR}

O espaço físico do escritório de contabilidade Conpor divide-se em três (3) departamentos de trabalho: fiscal, contábil e pessoal. Diante disso, optou-se por analisar a rotina de trabalho do contador em cada um desses departamentos, identificando o fluxo documental, ou seja, o caminho que o documento percorre durante a sua tramitação na organização, e consequentemente, a atuação do arquivista no escritório contábil.

A Figura 1, apresentada a seguir, representa um desses fluxos documentais. No caso, em relação a principal atividade desenvolvida no departamento fiscal da Conpor. 
Figura 1 - Fluxo documental no Departamento Fiscal da Conpor

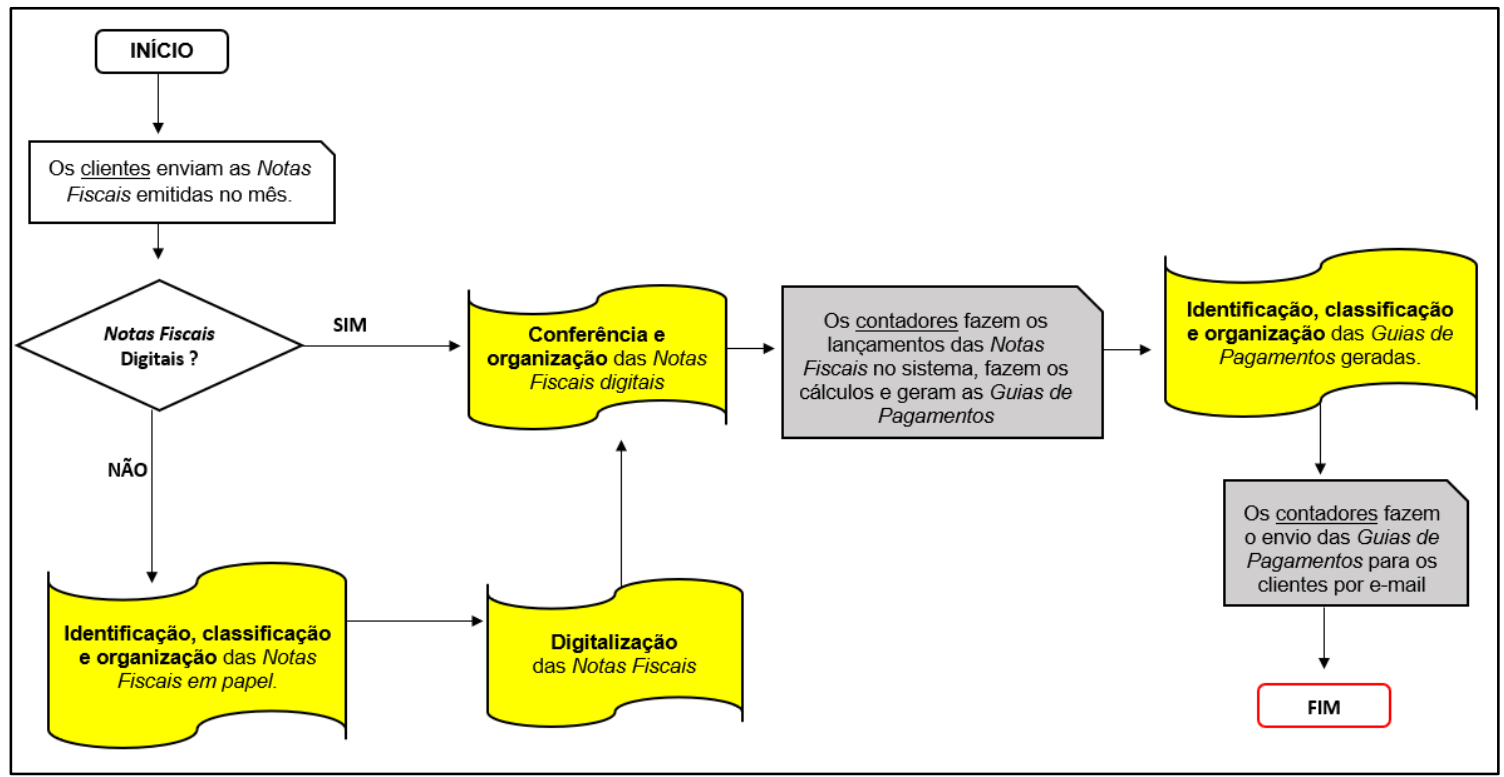

Fonte: Dados da pesquisa (2019).

Atividade do agente mediador arquivista

Atividade do contador

Percebe-se pela Figura 1 que o percurso da documentação no Departamento Fiscal começa com o acúmulo de documentos da tipologia documental "notas fiscais" no escritório, recebidas pelos clientes da contabilidade. Vale destacar que ao entrar no escritório, o conjunto documental das notas fiscais não são direcionados diretamente para os contadores. Há, conforme realçado nos três (3) primeiros quadros em amarelo da Figura 1, procedimentos prévios de tratamento e organização da massa documental.

Os referidos procedimentos devem ser realizados pelo agente mediador, que possui conhecimento sobre as notas fiscais, acumuladas em razão de atividades orgânicas, que são documentos arquivísticos, ou seja, é fundamental que o agente mediador possua conhecimentos técnicos e especializados da Arquivística. Vale destacar que a Lei $n^{\circ} 6.546$ de 4 de julho de 1978, aponta os arquivistas como os profissionais responsáveis pelo planejamento e organização dos documentos de arquivo de uma organização. Sendo assim, o agente mediador, primeiramente, deve verificar se as tipologias documentais recebidas 
são digitais ou impressas, para assim adotar qual o procedimento a ser feito.

Quanto aos documentos digitais, o agente mediador deve conferir e organizar as notas fiscais, para que assim, os contadores tenham acesso a tais documentos e possam fazer o lançamento no sistema e cálculos dos impostos devidos. Diante disso, verifica-se que o agente mediador atua na perspectiva da mediação da informação em conformidade com o que afirma Almeida Junior (2015). Ou seja, o agente mediador no departamento fiscal do escritório Conpor, realiza uma ação de interferência, organizando a informação disponibilizada na instituição, para subsidiar as atividades a ser exercida pelo contador.

Essa interferência do agente mediador ocorre, mais uma vez, conforme o destaque em amarelo na Figura 1, em que, o profissional identifica, classifica e organiza o conjunto de tipologia documental "guias de pagamento" antes de o contador enviar para os clientes. Tal ação proporciona a diminuição de possíveis erros de envio para os clientes e o tratamento da massa documental arquivística produzida no escritório de contabilidade. Isso motiva os profissionais que fazem parte do quadro dessa Instituição e proporcionam uma conscientização quanto à atuação do agente mediador.

Fica evidente, com o fluxo documental apresentado, que, na Conpor, o arquivista executa, principalmente, atividades indiretas de mediação da informação. Tais atividades possibilitam constatar a relevância da atuação do agente mediador da informação no escritório de contabilidade e a aproximação deste com o arquivista.

Sendo assim, é adequado afirmar que ao realizar as atividades indiretas de mediação no escritório de contabilidade, um arquivista está em contato direto com as informações contábeis, e assim, poderá interferir no processo de acesso e uso das informações. É importante sinalizar, que é preciso verificar os elementos de ambiência no escritório de contabilidade que podem influenciar ainda mais o processo de interferência do arquivista nas informações contábeis.

\subsection{Os Elementos de Ambiência que Favorecem o Processo de Mediação da INFORMAÇÃO NA CONPOR}

Os dados obtidos por meio da pesquisa de observação direta permitiram 
a identificação dos elementos da ambiência que favorecem o processo de mediação da informação contábil. $O$ intuito ao identificar os elementos de ambiência é destacar a visão do agente mediador, seja nos aspectos objetivos quanto nos subjetivos, em relação a elementos como a estrutura, a dimensão e ao fluxo comunicacional.

Em relação à estrutura, a partir da Figura 2 é possível observar que a sala de arquivo possui uma organização padronizada: a sala possui a sua identificação na porta e os armários estão organizados em caixas de cor azul, em ordem alfabética, pelo nome da empresa.

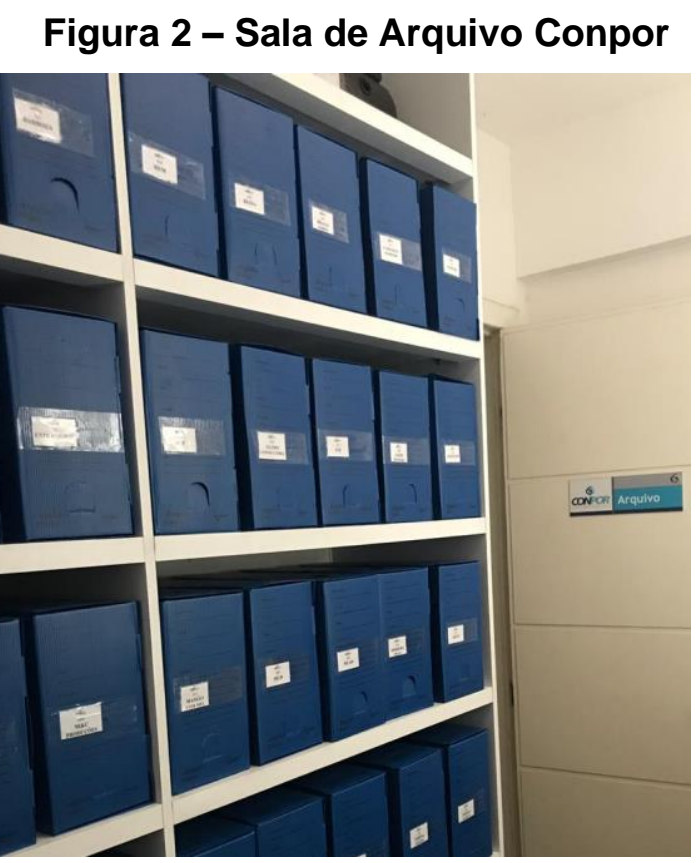

Fonte: Dados da pesquisa (2019).

É importante destacar que a presença de um espaço destinado para a guarda de documentos - a sala de arquivo - é fundamental para a valorização do trabalho do agente mediador da informação perante os contadores que trabalham no escritório. As atividades indiretas desenvolvidas pelo agente mediador como organizar e padronizar a sala de arquivo reforça ainda mais essa ideia, visto que isso permite com que os contadores percebam quem é o profissional responsável pela documentação e informação do escritório, ou seja, o agente mediador da informação torna-se valorizado na empresa.

Em relação à dimensão da sala de arquivo vale destacar, que foi observado o desconforto dos usuários para realização da consulta e análise dos 
documentos no local, visto que o espaço físico do arquivo é de pequenas dimensões - possui aproximadamente $7,3 \mathrm{~m}^{2}$. O contador, ao necessitar de um documento impresso presente na sala de arquivo, deve transportá-lo para a sua sala, realizando as consultas e análises pretendidas. Percebe-se o papel do mediador da informação em interferir na ambiência dos espaços informacionais, assim como defendido por Almeida Junior (2015). O agente mediador, então, desperta os contadores, por meio das atividades de mediação direta, a desenvolverem as consultas e análises documentais necessária em outro espaço mais adequado, tornando esse outro ambiente - a sala dos contadores - como mais um espaço informacional do escritório, gerando assim a aproximação entre o sujeito e a informação.

Outro aspecto a ser destacado refere-se à comunicação. $O$ arquivista, enquanto mediador da informação, deve estar atento a dialogia no ambiente, afinal, de acordo com Gomes (2014) a comunicação representa uma das dimensões essenciais da mediação da informação.

$\mathrm{Na}$ Conpor, de acordo com os dados da pesquisa, a sala dos contadores é o local em que o fluxo comunicacional entre os contadores acontece e em que existe a presença maior dos arquivos correntes. Desse modo, o local da sala dos contadores permite o fluxo comunicacional sem nenhuma barreira física, visto que não existem divisórias ou baías separando a mesa dos contadores. Podese dizer que a estrutura apresentada é benéfica para a mediação da informação, afinal, de acordo com Gomes (2014) o cenário com espaços de interação é essencial para a dimensão dialógica e consequentemente para a apropriação da informação e geração de novos saberes. Assim, o fato de a sala dos contadores não ser dividida por departamentos permite que aconteça a comunicação entre os diferentes usuários, no desenvolvimento de suas atividades profissionais, sob a observação e interferência do mediador da informação, que ao estar presente nesta sala auxilia os contadores, ocasionando assim a mediação direta da informação, por meio da comunicação.

Os resultados obtidos por meio da pesquisa de observação direta possibilitam a identificação de elementos de ambiência que agregam valor ao desenvolvimento do trabalho do agente mediador na Conpor. Vale destacar, 
porém, que alguns elementos, como, por exemplo, o espaço reduzido, afeta a ambiência, relativizando o conforto destinado aos usuários. Além disso, é possível observar que o agente mediador, ao ter conhecimento dos estudos em torno da Arquivologia, pode interferir e favorecer ainda mais a ambiência e, consequentemente interferir na tomada de decisão. Sendo assim, é importante destacar como ocorre o processo de interferência de um arquivista na tomada de decisão dos contadores.

\subsection{O Processo de Intervenção do Arquivista na Tomada de DeCisão dos CONTADORES NA CONPOR}

A partir dos dados obtidos por meio do questionário aplicado aos 7 (sete) contadores do escritório de contabilidade Conpor, buscou-se investigar se existe um processo de interferência do agente mediador da informação na Conpor na tomada de decisão do contador.

Quanto ao procedimento mais utilizado pelo contador, quando eles necessitam de um documento para desenvolver uma das suas atividades no escritório, conforme o Gráfico 1 a maior parte dos contadores demonstram uma ação autônoma em relação ao acesso à informação que precisam.

\section{Gráfico 1 - Procedimentos dos contadores para a busca dos documentos na Conpor}

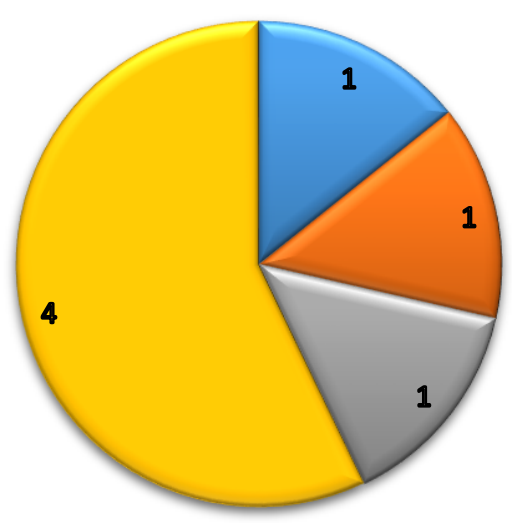

๑Vai diretamente na Sala de Arquivo e procura o documento na caixa da empresa. $\square$ Consulta o catálogo antes do acesso ao documento, para favorecer a localização.

$\square$ Pergunta ao profissional responsável pelo arquivo do escritório.

$\square$ Consulta o documento digital

Fonte: Dados da pesquisa (2019). 
Ainda em relação ao Gráfico 1, pode-se observar que quatro (4) contadores da Conpor indicaram que consultam o documento em sua forma digital, sendo esse o procedimento realizado pela maior parte dos respondentes. Essa resposta indica uma preferência quanto ao formato do documento, como também uma ação autônoma por parte do contador, ao realizar a consulta dos documentos a partir do Domínio Atendimento (software de gerenciamento documental). Entretanto, mesmo com esse nível de autonomia por parte dos usuários, a consulta a esses documentos só é possibilitada a partir da ação indireta de mediação da informação por parte do arquivista que realiza o processo de digitalização das documentações, bem como disponibiliza estes documentos para os usuários, no caso, os contadores. O processo de digitalização dos documentos faz parte da função arquivística, que segundo Rousseau e Couture (1998) favorece a difusão da informação.

Quanto à opção de consulta ao catálogo antes do acesso ao documento, para favorecer a localização, presente no Gráfico 1, também envolve uma atividade indireta de mediação da informação desenvolvida pelo agente mediador. Essa opção, conforme verificado, foi escolhida por 1 (um) dos contadores e demonstra certa autonomia na busca pela informação. Esse dado leva a inferência de uma ação direta de mediação da informação, que em algum momento o agente mediador deve ter orientado o usuário na busca pela documentação a partir do catálogo. Essa ação de orientar os usuários deve ser realizada periodicamente para que eles tenham consciência dos dispositivos que auxiliam no acesso e no uso da informação que necessitam.

Vale acrescentar que ao realizar a digitalização e a organização do acervo, o agente mediador tem acesso às informações dos documentos, o que favorece o conhecimento dele em relação à documentação existente tanto impressa quanto eletrônica. Esse aspecto leva a inferir que existe uma relação com a resposta apresentada, quando um respondente indica que "pergunta ao profissional responsável pelo arquivo no escritório". Esse dado confirma o reconhecimento e a confiança que os usuários possuem em relação ao agente mediador, contando com seu apoio na busca e acesso à documentação que precisa. 


\section{CONSIDERAÇÕES FINAIS}

Com base nos resultados desta pesquisa, foi possível identificar que existem fatores que contribuem para que o arquivista de um escritório de contabilidade medeie à informação contábil e auxilie o contador nas tomadas de decisões. Esses fatores estão ligados à ambiência e à comunicação estabelecida entre $o$ arquivista e os profissionais da contabilidade.

Ao mapear e descrever as atividades indiretas e diretas de mediação da informação que o arquivista desenvolve dentro de uma instituição contábil constata-se que o processo de organização e a classificação da massa documental faz com que esse profissional tenha contato direto com as informações contidas nos documentos de todos os setores da contabilidade (fiscal, contábil e pessoal). Dessa maneira, identifica-se que o profissional responsável pelo arquivo é capaz de auxiliar os contadores, seja para favorecer a agilidade na execução de uma atividade, seja para orientá-los em decisões a serem tomadas a partir do acesso às informações. Essas contribuições fazem do arquivista um mediador da informação contábil, realizando a mediação direta e indireta da informação.

Por meio desta investigação também foi possível constatar que os elementos da ambiência favorecem o processo de mediação da informação em uma instituição de contabilidade, sendo essencial que os agentes mediadores, no caso os arquivistas, junto aos gestores, interfiram, buscando melhorias nessas questões.

Por fim, os resultados da pesquisa sinalizam que existe um processo de interferência do arquivista enquanto mediador da informação na tomada de decisão do contador. Esse processo é realizado por meio das atividades de mediação direta e indireta. Entretanto, é preciso que o arquivista busque ser percebido na instituição contábil como um profissional que vai além da custódia e controle de acesso aos documentos. Os arquivistas no ambiente contábil, entre outras instituições, devem ser vistos também como agentes mediadores da informação que agregam valor positivamente às tomadas de decisões, por meio da mediação consciente da informação. 


\section{REFERÊNCIAS}

ALMEIDA JUNIOR, Oswaldo Francisco de. Mediação da informação: um conceito atualizado. In: BORTOLIN, Sueli; SANTOS NETO, João Arlindo dos; SILVA, Rovilson José da (org.). Mediação oral da informação e da leitura. Londrina: ABECIN, 2015. p. 9-32.

ALMEIDA JÚNIOR, Oswaldo Francisco de. Mediação da Informação, Sociedade e Biblioteca Pública. In: ALMEIDA JÚNIOR, Oswaldo Francisco de. INFOhome [Internet]. Marília: OFAJ, set. 2016. Disponível em: http://ofaj.com.br/espacoofajs_conteudo.php?cod=9. Aceso em: 1 out. 2019.

BRASIL. Lei $n^{\circ} 6.546$, de 4 de julho de 1978. Dispõe sobre a regulamentação das profissões de Arquivista e de Técnico de Arquivo, e dá outras providências. Diário Oficial da União: Seção 1, Brasília, D.F, p. 10296, 5 jul. 1978. Disponível em: https://www2.camara.leg.br/legin/fed/lei/1970-1979/lei-6546-4julho-1978-366508-publicacaooriginal-1-pl.html. Acesso em: 2 nov. 2019.

GIL, Antonio Carlos. Como elaborar projetos de pesquisa. São Paulo: Atlas, 2002.

GOMES, Henriette Ferreira; SANTOS, Raquel do Rosário. Bibliotecas universitárias e a mediação da informação no ambiente virtual: informações, atividades e recursos de comunicação disponíveis em sites. In: ENCONTRO NACIONAL DE PESQUISA EM CIẾNCIA DA INFORMAÇÃO, 10., 2009, João Pessoa. Anais [...]. João Pessoa: UFPB, 2009. Disponível em: http://200.20.0.78/repositorios/bitstream/handle/123456789/78/GT\%203\%20Txt $\% 202-\% 20$ Henriette_Raquel_corrigido.pdf?sequence=1. Acesso em: 28 nov. 2019.

GOMES, Henriette Ferreira. A dimensão dialógica, estética, formativa e ética da mediação da informação. Informação \& Informação, Londrina, v. 19, n. 2, maio/ago. 2014. Disponível em:

http://www.uel.br/revistas/uel/index.php/informacao/article/view/19994. Acesso em: 22 nov. 2019.

GOMES, Henriette Ferreira. Comunicação e informação: relações dúbias, complexas e intrínsecas. In: MORIGI, Valdir; JACKS, Nilda; GOLIN, Cida (org.). Epistemologias, comunicação e informação. Porto Alegre: Sulina, p. 91-107, 2016.

GOMES, Henriette Ferreira. Mediação da informação e protagonismo social: relações com vida ativa e ação comunicativa à luz de Hannah Arendt e Jürgen Habermas. In: GOMES, Henriette Ferreira; NOVO, Hildenise Ferreira (org.). Informação e protagonismo social. Salvador: EDUFBA, 2017.

LOPEZ, André Porto Ancona. O "Ser" e o "Estar" arquivista no Brasil de hoje: regulamentação e trabalho profissional. Revista Ibero-americana de Ciência 
da Informação, Brasília, DF, v. 1, n. 1, p. 219-232, jan./jun. 2008. Disponível em:

http://repositorio.unb.br/bitstream/10482/12897/1/ARTIGO_SerEstarArquivista.p df. Acesso em 20 nov. 2019.

MARCONI, Marina; LAKATOS, Eva. Fundamentos da Metodologia Científica. São Paulo: Ed. Atlas, 2007.

ROUSSEAU, Jean-Yves; COUTURE, Carol. Os fundamentos da disciplina arquivística. Lisboa: Dom Quixote, 1998.

SILVA, Lydianne Araújo Costa da. Reflexões sobre a disseminação de informações contábeis no ambiente digital. 2015. 25 f. Trabalho de Conclusão de Curso (Graduação em Arquivologia) - Universidade Federal da Paraíba, Joao Pessoa, 2015. Disponível em:

www.ccsa.ufpb.br/arqv/contents/documentos/073LydianneAraujoCostaeSilva.p df. Acesso em: 28 nov. 2019.

VIEIRA, Diego Hermys de Souza. A Gestão da Qualidade em um Escritório de Contabilidade no Município de Fortaleza. 2012. 75 f. Trabalho de Conclusão de Curso (Graduação em Ciências Contábeis) - Faculdade Cearense, Fortaleza, 2012. Disponível em:

http://www.faculdadescearenses.edu.br/biblioteca/TCC/CCO/A\%20Gestao\%20 da\%20Qaulidade\%20em\%20um\%20Escritorio\%20de\%20Contabilidade\%20no \%20Municipio\%20de\%20Forta.pdf. Acesso em: 28 nov. 2019.

YAMANOTO, Marina Mitiyo; SALOTTI, Bruno Meirelles. Informação contábil: estudos sobre a sua divulgação no mercado de capitais. São Paulo: Atlas, 2006.

\section{AGRADECIMENTO}

O presente trabalho foi realizado com apoio da Coordenação de Aperfeiçoamento de Pessoal de Nível Superior - Brasil (CAPES) - Código de Financiamento 001.

\section{THE ARCHIVIST AS A MEDIATOR OF THE INFORMATION AND ITS INTERVENTION FOR THE DECISION MAKING: A CASE STUDY AT CONPOR ACCOUNTING OFFICE}

\section{ABSTRACT}

Introduction: The mediation of information performed by the archivist in the accounting 
office, assisting accountants for decision making is the theme of this work. Objective: To analyze which factors contribute to the archivist of an accounting firm to mediate information and assist the accountant in making decisions. Methodology: The systematic direct observation technique was adopted to map and describe the activities developed by the archivist in the accounting office, as well as to identify elements of ambience that favor the information mediation process. For this purpose, this research was developed from the study of case performed at the Conpor accounting office. A questionnaire was also applied to the accountants of the office, in order to verify the existence of the intervention process of the archivist in the decision making of the accountant. Results: Among the most visible actions that identify the archivist as mediator of information in an accounting environment is technical activities, as well as the ambience and communication established between the archivist and accountants. Conclusion: It is necessary that the archivist seeks to be perceived in the accounting institution as a professional who adds value to decision making through direct and indirect mediation of information.

Descriptors: Information mediation. Account file. Archivist - Decision making.

\title{
EL ARCHIVISTA COMO MEDIADOR DE INFORMACIÓN Y SU INTERVENCIÓN PARA LA TOMA DE DECISIONES: UN ESTUDIO DE CASO EN LA OFICINA DE CONTABILIDAD CONPOR
}

\begin{abstract}
RESUMEN
Introducción: El tema de este trabajo es la mediación de la información realizada por el archivista en la oficina de contabilidad, ayudando a los contadores para la toma de decisiones. Objetivo: Analizar qué factores contribuyen al archivista de una empresa de contabilidad para mediar información y ayudar al contador a tomar decisiones. Metodología: Se adoptó la técnica de observación directa sistemática para mapear y describir las actividades desarrolladas por el archivista en la oficina de contabilidad, así como para identificar elementos de ambiente que favorecen el proceso de mediación de información. Para este propósito, esta investigación se desarrolló a partir del estudio de caso realizado en la oficina de contabilidad de Conpor. También se aplicó un cuestionario a los contadores de la oficina, para verificar la existencia del proceso de intervención del archivista en la toma de decisiones del contador. Resultados: Entre las acciones más visibles que identifican al archivista como mediador de información en un entorno contable se encuentran las actividades técnicas, así como el ambiente y la comunicación establecidos entre el archivista y los contadores. Conclusión: es necesario que el archivista busque ser percibido en la institución contable como un profesional que agrega valor a la toma de decisiones a través de la mediación directa e indirecta de la información.
\end{abstract}

Descriptores: Mediación de información. Archivo contable. Archivista - Toma de decisiones.

Recebido em: 22.05.2020

Aceito em: 18.11 .2020 